\title{
Training into psychological counselling should be an integral part of dental academic curriculum
}

\author{
N. D. Gupta ${ }^{1}$, Himanshu Trivedi ${ }^{2, *}$ \\ ${ }^{1}$ Professor, ${ }^{2}$ Assistant Professor, Dept. of Periodontics and Community Dentistry, Dr. Ziauddin Ahmad Dental College, Aligarh \\ Muslim University, Aligarh, Uttar Pradesh, India
}

*Corresponding Author:

Email: trivedi.heman@gmail.com

The quality of life depends on the overall thinking of an individual and same applies to the systemic and dental health of oneself. A clinician's way of dealing with the patient has a significant impact on overall treatment plan and outcome of the therapy. Institution of proper knowledge about oral health with astounding motivation paves the path for desired outcomes in the favour of both clinician as well as the patient. For instance early detection of oral cancer may prevent morbidity up to a certain extent, ${ }^{1}$ and dentist may prove to be of a vital importance at primordial and primary level of prevention. The most important factor while performing periodontal therapy is adequate plaque control which is impossible without proper patient education and motivation. ${ }^{2-4}$ To counsel patients for their oral health can itself be a herculean task because of time constraints and the lack of skills at the provider level. The same warrants an urgent attention of the stake holders at the policy making level as it may require inclusion into the academic curriculum of dental students. A counselling clinic with audiovisual and mechanical aids should be a part of every dental institution. Formal training into psychological counselling will inculcate the confidence and commitment in a dental student for desired objectives.

\section{Conflict of interest: Nil}

\section{References}

1. Ford PJ, Farah CS. Early detection and diagnosis of oral cancer: strategies for improvement. J Cancer Policy 2013;1:e2-e7

2. Jorkjind, L. and Birkeland, J. M.: Plaque and gingivitis among Norwegian children participating in a dental health program, Community Dent Oral Epidemlol, 1:41-46, 1973

3. Bjb'rn, A. L.: Dental health in relation to age and dental care, Odont Re,z, 25: suppl. 29, 1974.

4. Axelsson, P.: The effect of plaque control procedures on gingivitis, periodontitis and dental caries, Thesis, 1978 